\title{
Change in Classroom Dialogicity to Promote Cultural Literacy across Educational Levels
}

\author{
Merce Garcia-Mila ${ }^{1, * \mathbb{D}}$, Andrea Miralda-Banda ${ }^{1}$, Jose Luna ${ }^{1} \mathbb{D}$, Ana Remesal ${ }^{1}$, Núria Castells ${ }^{1}$ and \\ Sandra Gilabert ${ }^{2}$
}

1 Department of Cognition, Development and Educational Psychology, University of Barcelona, 08007 Barcelona, Spain; amiralda@ub.edu (A.M.-B.); joselunalujan110197@gmail.com (J.L.); aremesal@ub.edu (A.R.); nuria.castells@ub.edu (N.C.)

2 Department of Pedagogy, University of Rovira i Virgili (Tarragona), 43003 Tarragona, Spain; sandra.gilabert@urv.cat

* Correspondence: mgarciamila@ub.edu

Citation: Garcia-Mila, M.;

Miralda-Banda, A.; Luna, J.; Remesal,

A.; Castells, N.; Gilabert, S. Change in

Classroom Dialogicity to Promote

Cultural Literacy across Educational

Levels. Sustainability 2021, 13, 6410.

https://doi.org/10.3390/su13116410

Academic Editors: Jin Su Jeong and David González-Gómez

Received: 27 March 2021

Accepted: 2 June 2021

Published: 4 June 2021

Publisher's Note: MDPI stays neutral with regard to jurisdictional claims in published maps and institutional affiliations.

Copyright: (c) 2021 by the authors. Licensee MDPI, Basel, Switzerland. This article is an open access article distributed under the terms and conditions of the Creative Commons Attribution (CC BY) license (https:/ / creativecommons.org/licenses/by/ $4.0 /)$.

\begin{abstract}
In a highly diverse world, cultural literacy is an essential tool for living together in harmony, and dialogic teaching may be a way to promote and develop it among children and adolescents. We define cultural literacy as a set of attitudes (inclusion, tolerance, and empathy) and skills (dialogic argumentation) needed to understand others in our everyday lives. This paper focuses on the effect of a professional development programme to promote dialogue and argumentation to help children and adolescents overcome pre-existing stereotypes and prejudices and foster students' participation in discussions that contrast divergent viewpoints. This was done through debates on social responsibility issues, living together, and belonging as presented in books and short films addressing the following topics: citizenship, the celebration of diversity, democracy, globalisation, human rights, cooperation, sustainable development, and climate change. After the professional development programme was implemented, we video-recorded two of the 15 student-teacher interaction sessions during the project's implementation (session \#3 and session \#8). We analysed the data using a validated coding scheme across three educational levels (three preschool, four primary school, and four secondary school classrooms). We observed moderate gains in secondary education and preschool, but statistically significant gains in primary education.
\end{abstract}

Keywords: dialogic teaching; classroom discourse; K-12 education; cultural literacy

\section{Introduction}

In a highly diverse world, cultural literacy as a tool is essential to the achievement harmonious coexistence in a society. Dialogic teaching may serve to enhance its development by promoting inclusion.

We define cultural literacy as a set of attitudes (inclusion, tolerance, and empathy) and skills (dialogic argumentation) needed to understand others in our everyday lives [1]. Contrasting with our view, Hirsch [2], one of the most cited authors regarding cultural literacy, proposed the definition of cultural literacy as a fixed set of knowledge that might be used as a curriculum in formal education. Hirsch [2] argued that cultural literacy must include this knowledge, which leads to shared experiences.

In the Dialogue and Argumentation for Learning Literacy in Schools (DIALLS) project, we argue that defining cultural literacy as "knowledge attainment" reduces it to a monologic concept [1]. Our main criticism of this approach is the "monologic essence" of Hirsch's model, because it reflects a static and top-down imposed notion of culture. In DIALLS, we propose exploring the ways in which cultural identities and heritage are fluid and pluralistic. This leads to the concept of cultural literacy as no longer being simply about the knowledge of culture, but instead being considered a dialogic practice enabled through constructive encounters about what it means to be different from each other [1]. Giroux [3] 
also criticised Hirsch's approach as being elitist, based on the exclusion of cultural diversity (specifically ethnic and youth cultures) and the marginalisation of science and technology in favour of the more static elements of the culture. Accordingly, Kaufer [4] proposed an alternative theory of cultural literacy as "contributing" to what we share, such as democracy or freedom. Our perspective of cultural literacy also incorporates Riecken and Court's [5] assertion of the importance of the ability to critically process the explicit and implicit messages embodied in any culture, and, most importantly, of being rooted in the value of respect for individuals. These current refinements of the Hirsch model of cultural literacy help us to reconceptualise it as a dialogic concept that seeks to recognise the pluralistic nature of a multicultural world and the dispositions needed to navigate it. As Maine et al. [1] stated, "It is indeed the social interaction of people in cultural encounters that the concept of cultural literacy should address and seek to promote" (p. 386). This DIALLS reconceptualisation of cultural literacy is also based on Buber's [6] writings about the difference between the monologic mode of I-It and the dialogic mode of I-Thou, which is coherent with our reconceptualisation of cultural literacy as a dialogic practice [1] (p. 398).

Another reconceptualisation of cultural literacy is Farmer's [7]. She called attention to the inclusion of digital citizenship within the development of general cultural literacy. Digital citizenship refers to using technology safely, responsibly, critically, productively, and civically. This requires dealing with electronic information and participating actively and ethically in cyberspace, and acting wisely on electronic information for social and personal improvement. Although this is an interesting approach, it goes beyond the scope of the present project.

This paper presents results from the implementation of the DIALLS project in schools. The DIALLS project focuses on dialogue and argumentation as strategies to develop and consolidate inclusion, thus enhancing cultural literacy [8,9].

Designed to be implemented in preschool, primary, and secondary education, the DIALLS project encourages teachers to foster their students' participation in discussions that contrast divergent viewpoints, with the intention to develop inclusive, empathetic, and tolerant attitudes. The discussions focus on social responsibility issues such as living together and belonging, presented in books and short films on the topics of citizenship, the celebration of diversity, democracy, globalisation, human rights, cooperation, sustainable development, and climate change (see Figure 1 for the key concepts for promoting cultural literacy). Classroom dialogue becomes central in promoting inclusion, tolerance, and empathy through the development of students' dialogic argumentative skills [9].

The DIALLS professional development programme (PD) was implemented to support teachers to promote dialogue and argumentation that overcome pre-existing stereotypes and prejudices [10] and foster students' participation in discussions that contrast divergent viewpoints. More concretely, it aims to promote "teaching and learning through, for and as dialogue" ([11], p. 70). Kim and Wilkinson [11] and Asterhan et al. [12] described dialogic classrooms as settings in which the learning programme combines whole-class and smallgroup activities, in which participants share their ideas, express alternative viewpoints without feeling embarrassed, and, most importantly, listen to one another respectfully, eventually building a discourse based on collective ideas that have emerged during the discussion. In dialogic classes, the teachers' functions are to (1) formulate open-ended questions; (2) relinquish control of the students' discourse; and (3) ensure that students ask questions and evaluate each other's answers without intervening. 


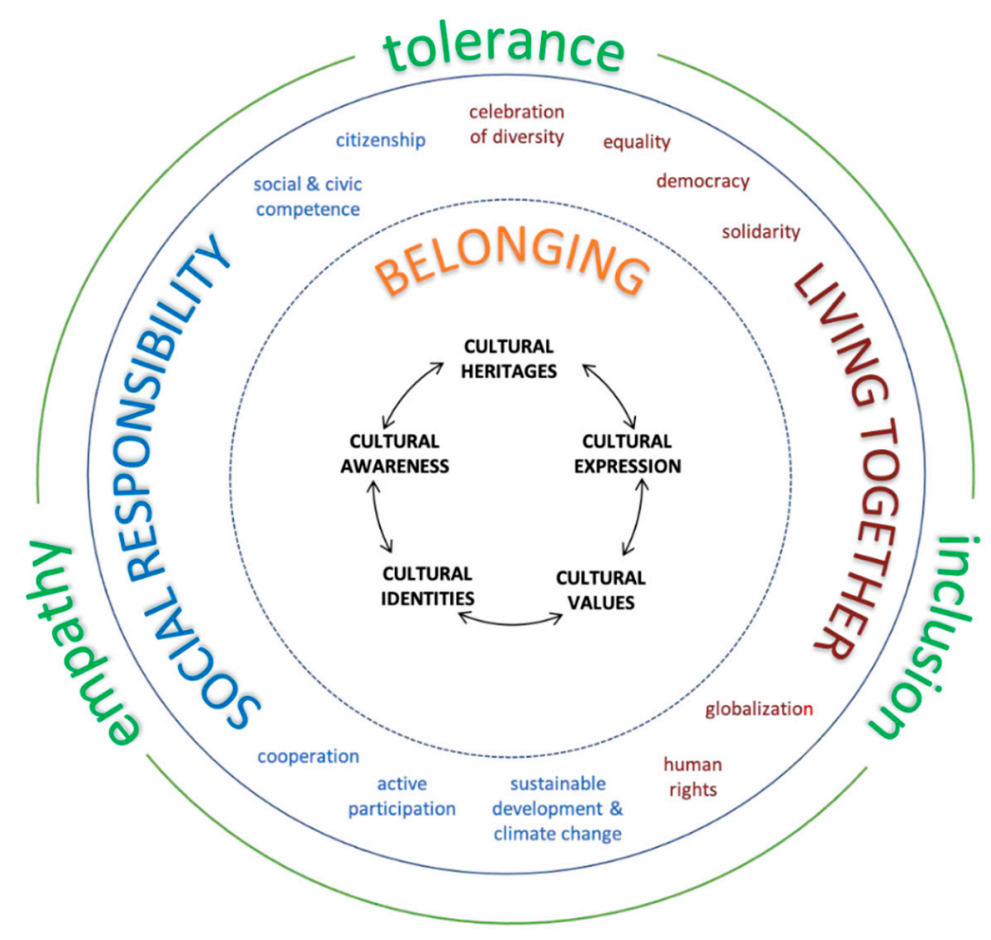

Figure 1. DIALLS wheel. Key concepts for promoting cultural literacy [9].

\subsection{Research on Dialogic Teaching}

Dialogic teaching involves students asking questions, expressing their points of view, and commenting on each other's ideas [13]. Despite differing approaches to dialogic teaching, there is consensus about the set of principles that characterise it [11-13]. A first essential condition is the use of a purposeful, planned discursive activity (such as the use of books or short films, each with lesson plans to stimulate debate about them) since dialogic teaching does not occur randomly or spontaneously. This approach must ensure that: (1) whole-class activities are combined with small-group activities; (2) participants have the chance to share their ideas, express alternative viewpoints, and, most importantly, listen to one another respectfully; (3) students feel free to explore and express their ideas without fear of embarrassment over "wrong" answers (i.e., in a supportive atmosphere), and they help each other to reach common understandings ([13], p. 6); (4) discourse is built on collective ideas that emerge during discussion (i.e., cumulative effect), through students integrating each other's contributions into coherent lines of thinking and understanding [13] (p. 6).

Reznitskaya and Wilkinson [14] summarised dialogic teaching as consisting of three main ideas: (1) teachers formulate open-ended, thought-provoking questions without right or wrong answers; (2) teachers relinquish control over the students' discourse; and (3) students ask questions and evaluate each other's answers without the need for teacher intervention, thus legitimising the students' voices [15]. As Chinn et al. [16] contended, these criteria promote student participation, provided that teachers ask students to explain their reasoning. Another prerequisite for successful dialogic teaching is intentional problematisation and problem-solving in the classroom [17]. These functions of dialogic teaching were very clearly operationalised by Michaels et al. [18], and O'Connor and LaRusso [19] in their Low-Inference Discourse Observation tool (LIDO), which was an essential reference for the analysis of dialogic interactions in the DIALLS project's implementation in the present study. The DIALLS project aims to foster cultural literacy through classroom dialogicity among K-12 students via teacher professional development. In the pursuit of this broader objective, the specific goal of the current paper was to analyse changes in classroom dialogicity at three educational levels (pre-primary, primary, and secondary education) following the implementation of the DIALLS project throughout the first eight sessions (see the project timeline Figure 2). 


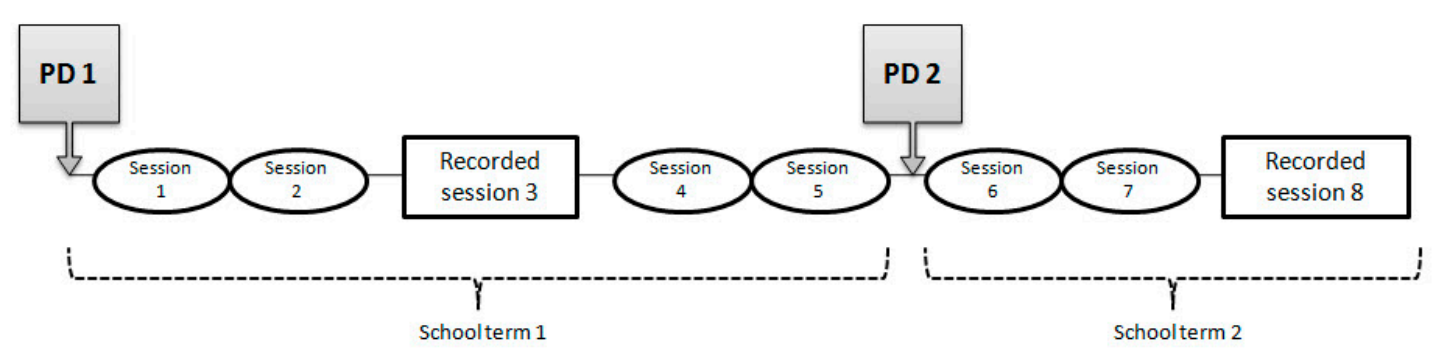

Figure 2. Project timeline.

The strategies employed by teachers render interaction essential to dialogic teaching [20-22]. In this section, we explore the use of dialogic teaching across educational levels.

A large body of research (see $[23,24]$ ) has highlighted the benefits of quality interaction between preschool teachers and pupils in improving schooling. Previous conclusions drawn from the study of interactions between these young pupils and their teachers highlight the need to pursue this line of research; in particular, studies exploring preschool classrooms from a dialogic perspective have drawn attention to the scarcity of educational dialogues that include knowledge accumulation and reciprocal interactions between teachers and children, with the classic classroom interaction pattern of initiation-responsefeedback (IRF) [25] being the most typical form of interaction [26]. Analysing teacherinitiated patterns of interaction, the authors of this latter study found that in high-quality teacher-initiated dialogues, the teacher took the time to listen carefully to their students interventions, providing space for the children to feel comfortable in sharing their ideas and encouraging respectful exchanges. Furthermore, in child-initiated interventions involving thought sharing, the role of the teacher was essential in facilitating dialogue. Another characteristic of preschool classrooms, reported by Muhonen et al. [26], is that children and teachers initiated a similar number of dialogic turns. By contrast, teacher-initiated dialogic moves appeared more frequently in primary school classrooms, compared to pupil-initiated moves.

Additionally, at the pre-primary level, Rasku-Puttonen et al. [27] described three patterns of dialogue: (1) the teacher interacts to demonstrate pupils' competence; (2) the teacher enhances pupils' participation; and (3) the teacher allows dialogic space for childinitiated sharing of ideas. Muhonen et al. [26] proposed three scaffolds to promote highquality interactions among preschoolers: (1) give space for pupils to express their ideas; (2) formulate open questions; and (3) ask them to explain their opinions. The authors noted that in low-quality interactions, the teacher mostly posed closed questions with right or wrong answers, typically promoting evaluation with dialogues that did not include thought exchanges and interactions that depended entirely on encouragement from the teacher.

In another study with 4- to 5-year-olds in Singapore, Bautista et al. [28] reported the need for more reciprocal dialogic forms of interactions at this educational level, contending that pupils need more opportunities to express themselves in classroom conversations. Other studies on dialogic teaching with preschoolers have focused primarily on the quality of the teachers' questions [29] and the pupils' participation [30], noting that the amount of teacher-pupil dialogue in classrooms with 3- to 6-year-old children is limited. According to Hännikäinen and Rasku-Puttonen [31], preschool teachers focus more on active participation through playful activities that aim to promote academic skills in children by fostering curiosity and motivation rather than on the quality of the participation itself.

Working with older students (5-, 6-, and 7-year-olds), Mercer et al. [32] observed that teachers used questions to promote active involvement, combining interactive dialogues (constructions that involve the pupils' points of view) and authoritative dialogues (constructions that do not involve the pupils' points of view). They also noted the frequent use of the classic IRF structure, concluding that it helped to foster dialogue. These authors criticised the lack of connection between the pupils' ideas and the views they discussed, observing that upper primary school teachers did not promote cumulative talk. Their findings are supported by those of Vrikki et al. [33], who reported that dialogue included 
high frequencies of elaborated and reasoned talk, but with a wide variation across classrooms. This variation was explained by the presence of hidden "pockets of excellence" (p. 97) connected to differences in primary school teachers' PD experience. In addition, they reported that the indicators of cumulative talk-such as inviting synthesis, summarising, comparing, or resolving two or more contributions among primary school students-were scarce. This low presence of dialogic moves in primary school teacher-pupil interactions was explained by the teachers' obligation to meet official curricular objectives [33], an argument also advanced by Muhonen et al. [15] and mentioned earlier in this section, in order to explain the differences they found between preschoolers and early primary school pupils. According to the authors, this finding indicates that activities in the preschool classroom may elicit more dialogue than in primary school, given that subject-related or disciplinary curriculum goals are more restrictive and demanding, leading teachers to feel that time used for discussion reduces "real teaching time" [34]. Thus, the focus is on participation and interaction per se in preschool (even when playing), but on academic learning in primary schools [31].

Focussing on secondary education, classic research by MacNeilley, et al. [35] identified three highly dialogic characteristics of secondary school teachers' practice: (1) authentic questions (with no predetermined answers); (2) questions that refer to previous answers; and (3) follow-up questions in response to students' replies as feedback (instead of a simple “OK") [33,36].

Sedova [22] described the difficulties in applying successful dialogic teaching in secondary school classrooms: "The theory of dialogic teaching is in principle unrealistic; the literature renders dialogic teaching in such an idealised way that it is very difficult for teachers to realise dialogic teaching with all its attributes in everyday practice" ([22], p. 286). Studies with secondary school students have mainly focused on the changes generated by teachers' PD and have obtained diverse results. In a study in Auckland, New Zealand, on the facilitation of small-group discussions by senior secondary school teachers, Davies et al. [36] observed changes after the teachers participated in a PD workshop on dialogic teaching. They found an increasing number of high-quality questions from the teachers, a significant reduction in the number of test questions, and an increase in the quality of the "questions asked to each other". Another important finding was the development of a positive attitude among the teachers towards the use of dialogue to foster deeper thinking in their secondary school students. Along these lines, Scott et al. [37] reported a shift in teachers' attitudes towards sharing control of the conversations, with the teachers becoming less authoritative. Our previous study [20] within the DIALLS project, also found a slight increase in dialogic discourse in secondary school classrooms, with a decrease in radial patterns of interaction (teacher-centred) and an increase in the teachers' attempts to encourage the students to respond to each other's viewpoints, thus increasing "accountability" [18].

Among the studies that reported a lack of effect of PD on dialogicity, Vrikki et al. [33] detected a low presence of indicators of cumulation [13], such as inviting, synthesising, comparing, and evaluating previous contributions, among teachers who reported some kind of previous PD. Vrikki et al. [33] concluded that good dialogic practice can occur in the absence of PD, explaining this lack of effect utilising two concepts: "scalability" and "sustainability" ([33], p. 87). The former refers to the difficulty of applying the considerable time and effort required to render PD effective. The latter refers to the lack of a long-term effect of some PD programmes.

\subsection{Research Question}

The above literature review indicates the need for more evidence of the effect of PD across teachers of preschool, primary, and secondary levels. In this paper, we focus on the effect of the dialogic teaching program implementation at these three educational levels. Our research question was: "Does a cultural literacy programme based on promoting dialogicity increase the quality of teachers' and students' dialogic interventions?" 
The underlying hypothesis of the present study was that the implementation of the cultural literacy programme based on dialogue and argumentation would affect participants' dialogicity at all educational levels. According to the literature, we expected to find differences in the effect size, with a more significant effect observed at higher educational levels.

\section{Materials and Methods}

\subsection{Design and Procedure}

We conducted a repeated-measures, cross-sectional observational study with two variables: educational level (three levels: preschool, primary, and secondary) and repeated sessions with two levels (sessions 3 and 8 ) (see Figure 2 for the session timeline).

The data came from the DIALLS project [10], which produced 15 lesson plans to be implemented in as many sessions over the course of one academic year. Initially, the intention was to video record sessions \#3, \#8, and \#15 for subsequent analysis. However, the COVID-19 lockdown affected the project, and only sessions \#1 to \#8 were eventually carried out. The materials used to stimulate classroom dialogue consisted of a selection of wordless books and short films. An example is the short film Baboon on the Moon [38], which presents a baboon who lives on the moon, and whose job is to light it up every evening. The baboon plays the trumpet while looking down to Earth, but the tune he plays is sorrowful, reflecting his homesickness. In this case, the session's goal is to encourage reflection on the concept of home and belonging. Appendices A and B, respectively, show the lesson plan for Baboon on the Moon and the four abstracts of the lesson materials used (see Table 1).

Table 1. Materials used at each educational level and in each session.

\begin{tabular}{lll}
\hline Educational Level & Session \#3 & Session \#8 \\
\hline Preschool & Ant [39] & Baboon on the Moon \\
Primary Education & Papa's Boy [40] & Baboon on the Moon \\
Secondary Education & Changeons!/Eccentric City [41] & Baboon on the Moon \\
\hline
\end{tabular}

The professional development (PD) course for teachers lasted $15 \mathrm{~h}$. An introductory $3 \mathrm{~h}$ PD session was held to recruit teachers. According to Fisher, after agreeing to participate, teachers then attended two all-day professional development sessions where they discussed dialogic strategies such as the importance of listening carefully to students' questions, challenging and probing students' thinking, preferably with open-ended rather than closed questions, and encouraging them to respectfully respond to each other in order to generate cumulative and accountable talk [42], as well as giving students sufficient time to respond. The teachers were also invited to scaffold their students' thinking by encouraging them to explain their opinions, while providing some essential tips for presenting reasoned arguments [14]. As part of the PD programme, all lesson plans were presented, and their implementation discussed with the teachers (see Appendix A). In session \#3, the multimodal texts varied across levels, while in session \#8, the film used for all three educational levels was Baboon on the Moon.

\subsection{Participants}

Eleven teachers (three preschool, four primary, and four secondary schools) and their students from three schools in the city of Tarragona, Spain, participated in this study. They were recruited as volunteers from the schools that collaborate with the Institute of Professional Development of the University. All the teachers and their students' parents / caregivers signed the corresponding consent forms. Table 1 presents a description of the participants. According to the International Standard Classification of Education (ISCED) [43], Table 2 shows the participants' school levels with the equivalencies to the ISCED. 
Table 2. Description of participants.

\begin{tabular}{cccccc}
\hline Teacher & Gender & Students & School Level & ISCED & Subject Matter \\
\hline Preschool 1 & Female & 15 & Preschool-3 & 0-Early Education & No \\
Preschool 2 & Female & 17 & Preschool-3 & 0-Early Education & No \\
Preschool 3 & Male & 20 & Preschool-3 & 0-Early Education & No \\
Primary 1 & Female & 25 & 3rd grade & 1-Primary Education & No \\
Primary 2 & Male & 27 & 3rd grade & 1-Primary Education & 1-Primary Education \\
Primary 3 & Female & 26 & 3rd grade & 1-Primary Education & No \\
Primary 4 & Female & 25 & 3rd grade & 2-Lower Secondary Ed. & Civic Ed. \\
Secondary 1 & Female & 12 & 9th grade & 2-Lower Secondary Ed. & Civic Ed. \\
Secondary 2 & Male & 15 & 9th grade & 2-Lower Secondary Ed. & Civic Ed. \\
Secondary 3 & Female & 27 & 9th grade & 2-Lowic \\
Secondary 4 & Female & 32 & 9th grade & 2-Lower Secondary Ed. & Language \\
\hline
\end{tabular}

\subsection{Design and Procedure}

The lesson plans developed in DIALLS were translated from English into Catalan (the official teaching language in our schools). Accordingly, the sessions were developed in Catalan. Transcription examples were translated from Catalan into English by a professional translator.

In pre-primary and primary school, the implementation did not connect to any specific subject matter. In secondary schools, the program was implemented in a language (Catalan class) or a civic education class. Video recordings from lessons \#3 and \#8 were transcribed. The sessions consisted of three types of activity: teacher-guided whole class debate, student small-group discussion, and teacher-guided small groups initiated when students asked for help or the teacher spontaneously engaged in their conversation. Given that our focus was on teacher-student interaction, we only considered in the present analysis those segments of interaction in which teachers intervened; small-group discussions were excluded from the analysis. As mentioned above, the materials used in session \#3 were different for each educational level. In session \#8, the three groups used the same material (see Table 2; Appendix B shows a summary of the four materials used).

The unit of analysis was each participant's speech turn, coded according to a lowinference discourse observation (LIDO) tool $[18,19]$. The coding scheme provides six ordinal categories for teachers and five for students, which indicate the level of dialogicity of the interaction, where 1 indicates the maximum and 5-6 indicates the minimum. Table 3 presents the corresponding teacher and student categories. We double coded all transcriptions and calculated reliability (Krippendorf $\alpha=0.73$ ). Discrepancies were resolved by discussion until consensus.

Table 3. LIDO categories.

\begin{tabular}{l} 
Teachers \\
\hline T1: Encouraging students to react to their classmates' contributions; \\
T2: Prompting and following up to deepen contribution; \\
T3: Active listening to maintain the interaction; \\
T4: Posing open questions; \\
T5: Posing semi-open questions; \\
T6: Posing single-answer questions. \\
\hline Students \\
\hline S1: Directly addressing another classmate; \\
S2: Indirectly referring to another classmate's intervention; \\
S3: Offering reasoning to support claim; \\
S4: Elaborated utterance presenting full ideas; \\
S5: Offering only minimal utterance response (i.e., only a single clause).
\end{tabular}




\section{Results}

We begin the Results section with a general picture of the level of dialogicity of teachers' and students' discourse in the early stages of the programme (in session \#3) in order to identify the categories most frequently used at each educational level before the intervention and to determine any differences in the use of categories. Since the result of a Kruskal-Wallis comparison of the total number of moves according to educational level was not significant $\left(\chi^{2}(\right.$ d.f. $\left.=2, n=11)=1.7, p=0.43\right)$, we worked with frequencies. The mean numbers (SD) of total moves for pre-primary, primary, and secondary education were: 278 (58), 241 (135) and 195 (88), respectively. We performed a within-subjects analysis (Friedman) for each level, considering the teacher and student categories, respectively, and then investigated how this initial picture changed following the programme intervention to analyse its effect on each educational level. We focused on changes in the degree of dialogicity in pre-primary, primary, and secondary school classes by comparing session \#3 with session \#8. Since the data did not follow a normal distribution, we applied the Wilcoxon nonparametric paired test to each educational level, with sessions as a withinsubjects factor.

\subsection{Distribution of Categories by Educational Level in Session \#3}

We begin this section by providing a picture of dialogicity in session \#3, showing the presence of each dialogic category (for teachers and students, respectively) at each educational level (Figure 3). Figure 3 and Tables 4 and 5, for teacher and student categories, respectively, show the distribution of frequencies according to session and educational level.

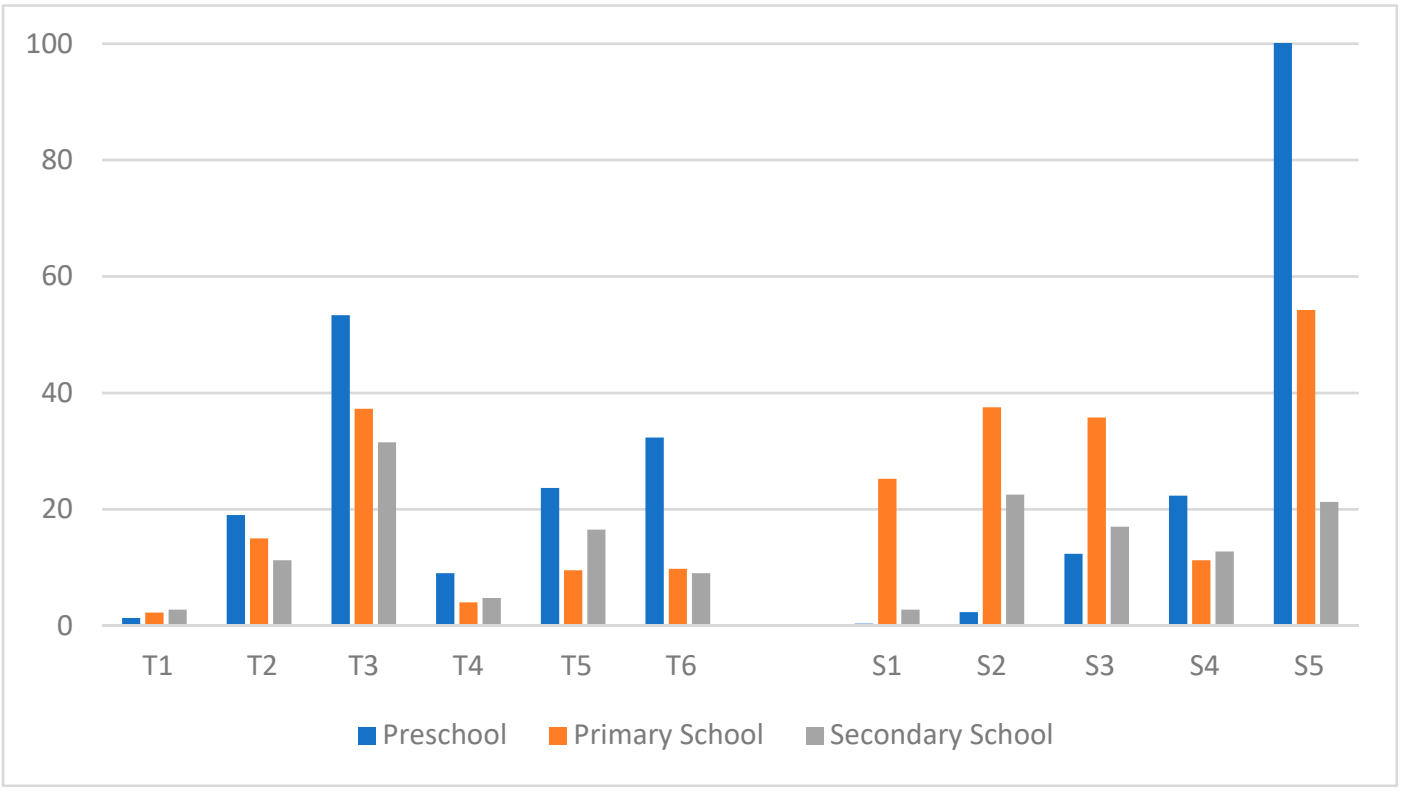

Figure 3. Distribution of frequencies of categories (session \#3) across the three educational levels.

In session \#3, for the preschool sample, T3 was the most frequent teacher category, followed by T5 and T6 $\left(\mathrm{Chi}^{2}(\right.$ d.f. $\left.=5, n=3)=21.1, p=0.03\right)$, while for the pupils, S5 was the most frequent category $\left(C h i^{2}(d . f .=4, n=3)=9.8, p=0.04\right)$ (see Figure 3).

Primary school pupils showed a similar pattern to the preschoolers; the most frequent category for pupils was S5 $\left(\mathrm{Chi}^{2}(\right.$ d.f. $\left.=4, n=4)=8.6, p=0.07\right)$, while for teachers, once again, it was T3 $\left(\mathrm{Chi}^{2}(\right.$ d.f. $\left.=5, n=4)=15.8, p=0.007\right)$. 
Table 4. Means (SD) for the distribution of teacher categories for session \#3 and session \#8 across educational levels.

\begin{tabular}{ccccccc}
\hline \multicolumn{7}{c}{ Session \#3 } \\
\hline T1 & T2 & T3 & T4 & T5 & T6 \\
\hline $\begin{array}{c}\text { Pre- } \\
\text { primary }\end{array}$ & $1.3(1)$ & $19.0(16)$ & $53.3(24)$ & $9.0(8)$ & $23.7(12)$ & $32.3(18)$ \\
Primary & $2.2(3)$ & $15.0(7)$ & $37.2(24)$ & $4.0(1)$ & $9.5(2)$ & $9.75(7)$ \\
Secondary & $2.7(2)$ & $11.2(9)$ & $31.5(29)$ & $4.7(4)$ & $16.5(11)$ & $9.0(5)$ \\
\hline & & & Session \#8 & & & \\
\hline & $\mathrm{T} 1$ & $\mathrm{~T} 2$ & $\mathrm{~T} 3$ & $\mathrm{~T} 4$ & $\mathrm{~T} 5$ & $\mathrm{~T} 6$ \\
\hline Preschool & $3.7(3)$ & $46.7(13)$ & $62.0(15)$ & $8.0(3)$ & $18.0(10)$ & $8.0(2)$ \\
Primary & $4.2(3.4)$ & $22.5(8)$ & $61.7(13)$ & $6.2(5)$ & $8.7(4)$ & $4.2(2)$ \\
Secondary & $5.0(5)$ & $12.0(9)$ & $22.7(25)$ & $3.7(2)$ & $11.2(13)$ & $9.0(8)$ \\
\hline
\end{tabular}

Table 5. Means (SD) for the distribution of student categories for session \#3 and session \#8 across educational levels.

\begin{tabular}{cccccc}
\hline \multicolumn{7}{c}{ Session \#3 } \\
\hline S1 & S2 & S3 & S4 & S5 \\
\hline Preschool & $0.3(1)$ & $2.3(4)$ & $12.3(7)$ & $22.3(13)$ & $102(23)$ \\
Primary & $25.2(38)$ & $37.5(47)$ & $35.7(19)$ & $11.2(3.5)$ & $54.2(28)$ \\
Secondary & $2.7(2)$ & $22.5(14)$ & $17.0(15)$ & $12.7(3)$ & $21.2(18)$. \\
\hline \multicolumn{7}{c}{ S1 } & S2 & S3 & S4 & S5 \\
\hline Preschool & $4.3(1)$ & $1.0(1)$ & $30.0(3)$ & $57.3(19)$ & $66.0(19)$ \\
Primary & $4.7(5)$ & $3.2(4)$ & $27.7(11)$ & $52.2(23)$ & $37.5(13)$ \\
Secondary & $2.7(3)$ & $24.2(14)$ & $12.5(15)$ & $8.2(5)$ & $22.5(21)$ \\
\hline
\end{tabular}

We performed the same analysis for the secondary school participants. The frequency of use of each discourse category was similar to that of the earlier educational levels, although the distribution of the categories was slightly more homogeneous at this level. Friedman's tests yielded marginally significant differences for teachers $\left(\operatorname{Chi}^{2}(d . f .=5, n=4)=10.6\right.$, $p=0.056)$ and for students $\left(C_{h i}^{2}(d . f .=4, n=4)=9.36, p=0.053\right)$. The most frequent category for teachers in secondary education was again T3, while for students, the most frequent were S2 and S5.

\subsection{Distribution of Categories by Educational Level in Session \#8}

As in the previous section, we performed Friedman's test to identify the most frequent categories. For teachers in preschool and primary education, T2 and T3 were the most frequent categories $\left(C h i^{2}(\right.$ d.f. $=5, n=3)=14.1, p=0.012$ for preschool and $\operatorname{Chi}^{2}($ d.f. $=5, n=4)$ $=14.7, p=0.011$ for primary school), whereas we found no differences in secondary school $\left(C h i^{2}(d . f .=5, n=4)=8.4, n s\right)$. The same analysis was performed for the student categories, and significant differences were obtained for each educational level. For preschoolers $\left(\mathrm{Chi}^{2}\right.$ $($ d.f. $=4, n=3)=12, p=0.017)$ and primary school pupils $\left(C h i^{2}(d . f .=5, n=4)=14.3\right.$, $p=0.006), \mathrm{S} 3, \mathrm{~S} 4$, and S5 were the most frequent categories, and S2 and S5 were the most frequent categories for secondary school students $\left(\operatorname{Chi}^{2}(d . f .=5, n=4)=12.8, p=0.012\right)$ (see Figure 4). 


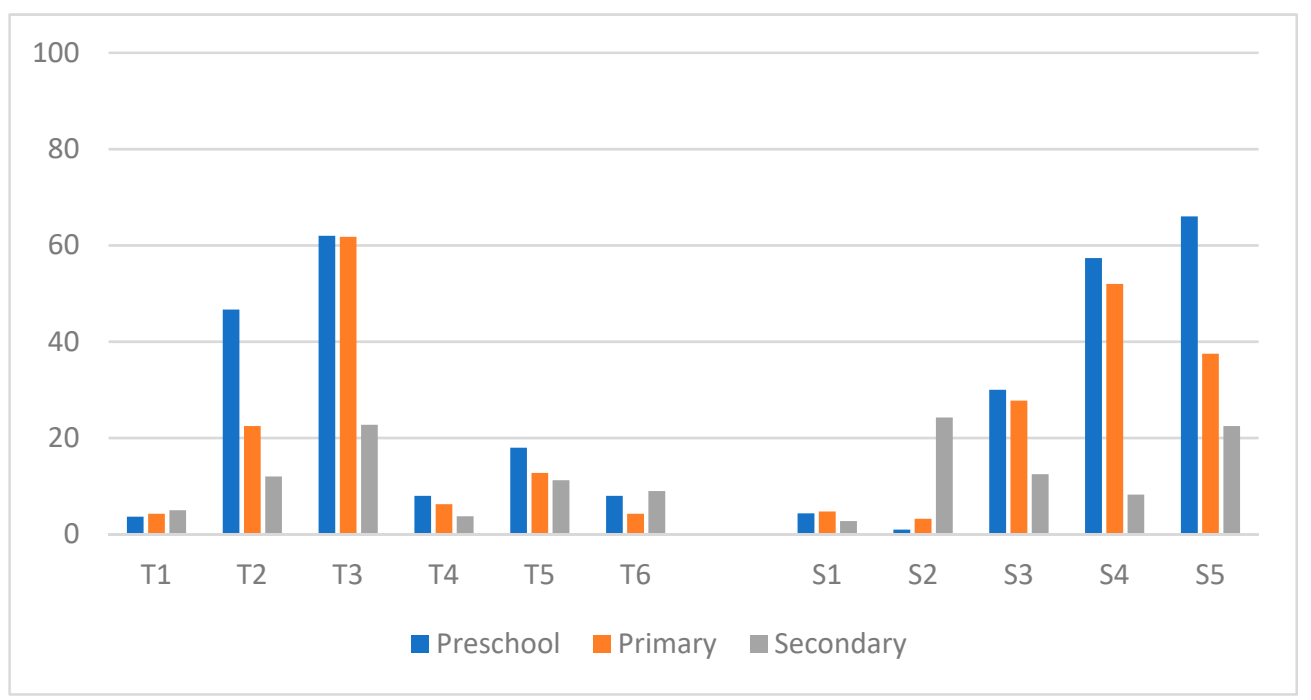

Figure 4. Distribution of category frequencies (session \#8) across the three educational levels.

\subsection{Differences between Session \#3 and Session \#8 across Educational Levels}

In this section, we narrow the analysis to each educational level, focusing on the differences between Session \#3 and Session \#8 to address the research question concerning the effect of the intervention and whether this effect was different across the three educational levels. The mean frequencies for teachers' (T1, T2, T3, T4, T5, and T6) and students' (S1, S2, S3, S4, and S5) dialogic moves in the two sessions for each educational level are presented in Tables 4 and 5, respectively. The results for each educational level and each category are shown in Figure 3 for session \#3 and in Figure 4 for session \#8.

According to Michaels et al. [18] and O'Connor and LaRusso [19], T1, T2, and T3 of the LIDO tool are the most dialogic categories. Thus, these were the categories that were expected to increase in frequency as a result of the implementation of the programme. We performed a Wilcoxon paired test for each discourse category and each educational level to identify statistically significant changes in category frequency from session \#3 to session \#8. As regards the student categories, S1, S2, and S3 reflect high levels of dialogicity, while S4 corresponds to more elaborated answers. Therefore, these were expected to increase in frequency from session \#3 to session \#8, whereas S5, denoting nondialogic moves, was expected to decrease. We indeed observed several of the expected patterns, but they were not statistically significant. Primary education was the only level that yielded significant differences. As expected, T2 and T3 increased significantly at this level: T2 ( $Z=-1.8, p<0.034$ (one-tail significance)), and T3 $(Z=-1.7, p<0.033$ (one-tail significance)). As regards the students, $\mathrm{S} 4$ showed a significant increase $(Z=-1.8, p<0.034$ (one-tail significance)). These results indicate a slight tendency towards a higher dialogicity, which can be observed by comparing data from Figures 3 and 4. In Section 3.4, we present dialogue excerpts from session \#8 [Baboon on the Moon (see Appendix A for the lesson plan for secondary education)].

\subsection{Illustration of Classroom Diaologicity with Discourse Excerpts across School Levels}

To illustrate the varying dialogicity across school levels, we present a set of classroom excerpts in this section. All examples are from session \#8, namely the lesson focused on the short film Baboon on the Moon. Discussions took place in Catalan, the official language, and were translated into English for this paper by the authors.

In the following example from preschool, we demonstrate teachers use active listening based on T3 moves. However, in many cases, this is not enough to support pupils as young as 5 or 6 years old to be able to expand on their answers. For instance, student \#1 first answers with reasons (S3), but later only uses monosyllables (S5):

Student \#1: From Tarragona (S5). 
Teacher: Ah, and why were you living in Paris? (T3).

Student \#1: Because I was born there (S3).

Teacher: But you didn't stay there for a long time, did you? (T3).

Student \#1: No (S5).

Teacher: And that's why you are not from Paris anymore, right? (T5).

Student \#1: No (S5).

In the following example from primary education, the teacher opens a dialogue about why the character in the short film feels lonely and homesick, in order to develop the concepts of home and belonging. The students' different responses were coded as S4 and T3. The dynamics of the discourse encouraged students to provide their answers, elaborating responses that attempt to explain the character's feelings.

Teacher: Ok. Baboon doesn't give up, right? Although he is lonely... He gets up and turns on the light of the moon. Student 1?...

Student 1: If I had to choose between family or being alone, I'd always choose family (S4)

Student 2: Home is where you like to be and where you're happy; that's why there's the expression "home sweet home". (S4) [ ... ]

Student 3: Home is where your father, your mother and your family are, and is also what you need to live, like water... (S4)

Student 2: Home is where your heart is (S4)

In the secondary education school example, we observed that the teacher used discourse strategies in line with the dialogic teaching professional development, i.e., focusing on both dialogicity and cumulativity of joint discourse. We also observed a typical pattern among students (reported in [20]), in which the teacher opened the discussion with a semi-open question (T5), one student responded with an elaborated answer (i.e., S4), and a peer responded with a simpler one (i.e., S5). Despite this, the teacher tended to continue promoting dialogue through active listening (T3) without achieving positive results because the students continued to respond with simple answers (S5):

Teacher: You know all the rules of dialectical conversations, don't you? Basically, all options, opinions have to be respected and they have to be argued, okay? What do you think the meaning of the film is? (T5).

Student \#1: I think that it is like a representation of many people going to work away from home and working in a job that they may like but being a long time alone and away from home and excluded. This is why he seems sad. (S3).

Teacher: Very good, very interesting. Does the other group agree? (T1).

Student \#2: We think that... well... it's a person or whatever works on the moon turning it on and off every day so it's day and night and... of course it's alone and through music he feels better and expresses his feelings. (S3).

Teacher: What makes you think that he is sad and melancholic? (T2).

Student \#1: He was playing sad songs with his trumpet. (S4).

Student \#3: Also, he is crying and he misses home (S2).

Student \#1: Well, not only in that moment, his life is sad, he wakes up and does not smile at all. It is very dark, no lights, nothing happens (S3).

Student \#4: And boring (S2).

Teacher: Very well! So, what makes a house be a home? (T4).

\section{Discussion}

In agreement with the reports of other authors [33] concerning high variability in the use of each discourse category, our findings show that the intervention only had a weak effect in both preschool and secondary education in all of the categories analysed. 
In contrast, the results observed in secondary education could be explained by the fact that this group were more focused on reaching academic goals [31]. Fostering dialogicity in primary education showed potential, coinciding with the time when pupils' dialogic skills are emerging and require consolidation.

In the early stages of the project, immediately after the first PD session, the three groups presented a relatively homogeneous pattern. The most frequent dialogic category for teachers at all three educational levels was T3 (active listening to maintain the interaction). This result is consistent with other research findings regarding the positive effect of PD in fostering dialogic teaching strategies $[44,45]$. Nevertheless, T3 interventions were followed by $\mathrm{T} 5$ (posing semi-open questions) and T6 (posing single-answer questions), bearing in mind that T5 and T6 are the least dialogic categories. Correspondingly, for students, the most frequent category was S5 (simple clause response; also the least dialogic).

Only primary education showed significant changes after the PD sessions and the implementation of the programme. Besides the possible influence of small sample size, our lack of significant results in preschool supports the conclusion reached by Muhonen et al. [15], namely, that there is a lack of reciprocal interaction between teachers and children at this age, a situation that hinders cumulative knowledge. Furthermore, in agreement with other studies involving 3- to 6-year-old children, the lack of dialogicity in the teachers' questions [29] and the children's responses [30] in our sample indicates that changes in teacher-pupil interaction for the improvement of dialogicity may have limited value. We interpret the results for preschoolers in terms of the low-level linguistic skills of the 4- to 5 -year-olds, which their speech difficult to capture using the LIDO coding scheme despite the teachers' efforts to foster more complex discourse. The preschoolers' answers ware usually incomplete or poorly elaborated, upon due to their lack of linguistic resources to properly engage in the discourse as proposed. In this sense, our results coincide with Vrikki et al.'s claim about the scarcity of long-term PD programmes in research on dialogicity, given that it is not easy to transform classroom dialogue into quality dialogic interaction at these ages. Specific guidelines are required to enable teachers to overcome old inertias in the classroom dialogue (i.e., closed questions and accepting unjustified answers).

By contrast, in primary education, the changes due to the intervention were as expected; we identified significant increases in T2 (prompting and following up to extend the contribution), T3 (active listening to maintain the interaction), and S4 (elaborated utterance presenting full ideas). According to Muhonen et al. [15], the categories that we observed most frequently in teachers- 22 and T3 - can be considered precursors of dialogicity. Listening carefully and making pupils feel comfortable in sharing their ideas freely and respectfully favours high dialogicity (S4). In addition, we defend this increase in S4 in primary education as a prerequisite for more elaborated responses beyond closed questions (T6) and answers (S5) in order to stimulate cumulative talk [32]. Indeed, cumulative talk was strongly enhanced by the PD sessions, to the extent that some teachers posted these guidelines on the classroom blackboard together with an explanation of what an argument is.

Furthermore, as we observed in the excerpts from primary school pupils' contributions, the teachers' responses to children's initiations were essential in facilitating dialogue [26]. Our data also highlight the effectiveness of the scaffolds proposed by Muhonen et al. [14] to facilitate suitable interventions (see lesson plan in Appendix A): (1) giving space for the children to express their ideas (also proposed by Bautista et al. [28]) (T1); (2) formulating open questions (as opposed to closed questions) (T4); and (3) asking the children to explain their opinions (T2). Our results with primary school pupils are also supported by those reported by Vrikki el al. [33] regarding the low presence of the dialogic moves of inviting, comparing, or resolving two or more contributions (T1 and T2), thus generating little cumulative talk. The heterogeneity of our findings may be related in some degree to the small sample size., but our interpretation of this finding coincides with that of Vrikki et al. [33], namely that it is probably due to "pockets of excellence" (p. 97) linked to differences in primary school teachers' PD experience. 
In our secondary education sample, slight changes happened as a result of the intervention. We did not observe the dialogic characteristics reported by MacNeilley, et al. [36]: (1) the presence of authentic questions (T4); (2) questions that refer to previous answers (T1); (3) follow-up questions in response to students' replies as feedback (T2) [35]. Along these lines, and in contrast to the results reported by Davies et al. [36] regarding secondary school teachers' dialogic moves, we did not observe increases in the number of high-quality questions from teachers (T3), or in the quality of the questions asked to each other (T1), nor did we observe any significant reduction in the presence of closed questions (T5 and T6). Our results endorse the concepts of scalability (i.e., the difficulty in devoting sufficient time and effort to render PD effective) and sustainability (i.e., the lack of analysis of long-term PD effects raised by Howe and Mercer [39]).

However, previous work by our team [20] showed an increase in dialogicity (T1, T2, and T3) throughout the implementation of the programme in a secondary school, with a radial teacher-centred pattern. For their part, Scott et al. [37] found that secondary school teachers shifted towards a less authoritative stance, with a more control-sharing pattern of dialogue and an increase in the encouragement given to the students to respond to each other's viewpoints, thus increasing "accountability" [18]. This occurred in combination with a significant increase in T2, whereby teachers encouraged students to expand on their responses. We found a connection between the dialogic moves of teachers and students, indicating that the lesson plans were effective in fostering dialogicity.

Our data show that the DIALLS program as implemented was effective in helping children and adolescents to overcome pre-existing stereotypes and prejudices and foster students' participation in discussions that contrast divergent viewpoints. We emphasise the use of a purposeful, planned discursive activity through books or short films, supported by lesson plans to prompt debate about these issues. Based on out results about the change in dialogicity, we conclude that cumulative, supportive, and intentional dialogue improved progressively over the course of the sessions. This also showed the increase in mutual understanding and knowledge co-construction about social responsibility issues, living together and belonging as presented in the lesson materials (citizenship, diversity, democracy, globalisation, human rights, sustainable development, and climate change).

We expected a higher impact on the secondary school level; however, our results show that primary education was the level with the highest impact. An uncontrolled factor was the teacher. Therefore, we could interpret the lower impact in secondary education in terms of class motivation and differences in teachers' and students' engagement with the project.

The present study emphasises the need to promote dialogic teaching at all educational levels, especially among secondary school students. Promoting dialogue is a major goal in European educational policy because it contributes to the development cultural literacy, an essential ability regarding issues such as climate change, sustainability, and immigration [46].

\section{Limitations of the Study}

Our study had two main limitations. The first one was the small sample size, which meant that we were able to identify only a limited number of significant trends, despite the noteworthy trends observed in Figures 3 and 4. The second limitation, a general problem faced in all analysis of dialogicity, was the lack of sufficient extended and intensive professional development [33]. However, our results are nevertheless promising because they indicate that a larger sample and a more extensive programme might well yield interesting results.

Author Contributions: Conceptualisation, M.G.-M., A.R., and N.C.; methodology, M.G.-M. and A.R.; coding and reliability, A.M.-B., J.L., S.G., A.R., N.C., and S.G.; formal analysis, M.G.-M. and A.M.-B.; data curation, A.M.-B., J.L., A.R., N.C., and S.G.; writing-original draft preparation, M.G.M.; writing-review and editing A.M.-B., J.L., A.R., N.C., and S.G.; supervision, M.G.-M.; funding acquisition, M.G.-M. All authors have read and agreed to the published version of the manuscript. 
Funding: This research was supported by the Spanish Ministry of Science, Innovation and Universities (RTI2018-097289-B-I00) and the European Union.
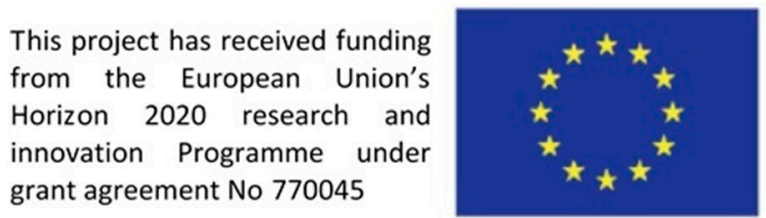

Institutional Review Board Statement: The study was conducted according to the guidelines of the Declaration of Helsinki, and approved by the Institutional Review Board (or Ethics Committee) of The University of Barcelona.

Informed Consent Statement: Informed consent was obtained from all subjects involved in the study.

Data Availability Statement: Data are stored in the open access repository: 10.5281/zenodo.4058182

Conflicts of Interest: The authors declare no conflict of interest.

\section{Appendix A}

Adaptation of the lesson plan for session \#8 for the film Baboon on the Moon: secondary school students (age 14/15) (adapted from Dialls 2018 [9]).

\begin{tabular}{|c|c|c|}
\hline \multicolumn{3}{|c|}{ Lesson Overview | Session Number 8} \\
\hline Cultural Text: & \multicolumn{2}{|c|}{ Baboon on the Moon (Film) [40] } \\
\hline Age & \multicolumn{2}{|l|}{ Years 14-15 } \\
\hline Theme & \multicolumn{2}{|l|}{ Empathy } \\
\hline (Sub-Theme) & \multicolumn{2}{|l|}{ Belonging } \\
\hline \multirow[t]{2}{*}{ Learning Goals } & $\begin{array}{l}\text { Dialogue and } \\
\text { Argumentation }\end{array}$ & Share ideas/reach consensus \\
\hline & $\begin{array}{l}\text { Cultural Learning } \\
\text { Objective }\end{array}$ & $\begin{array}{l}\text { To understand the impact of living conditions in } \\
\text { intercultural relationships; to reflect on the } \\
\text { influence of loneliness in the Other; to reflect on } \\
\text { "home" as a concept. }\end{array}$ \\
\hline \multicolumn{3}{|l|}{ Lesson Procedure } \\
\hline $\begin{array}{l}\text { Share film/book } \\
\text { (including pre-share } \\
\text { task if appropriate) }\end{array}$ & \multicolumn{2}{|c|}{$\begin{array}{l}\text { (Students are in the lab organised in small groups. Each group has } \\
\text { access to a computer). The teacher will not give any a priori instruction, } \\
\text { and students will observe the film and reflect on what this one conveys } \\
\text { to them. }\end{array}$} \\
\hline
\end{tabular}
to them.

After watching the film, the teacher will guide a whole-class discussion on the generic subject "what is a home?". Eventual questions/sub-themes to be handled: nostalgia; empathy; home as a concept; the meaning/emotional burden of the music; the origins of the main character of the film; what the moon represents, etc. Some

Activity to stimulate questions that can guide the discussion:

thinking (optional short task) (a) Where does Baboon come from?

(b) Why is he on the Moon?

(c) Does he like it being there?

(d) What would you do if you were Baboon? How would you feel?

(e) Where is Baboon's home? On the Moon or on Earth?

(f) $\quad \ldots . .$. 
Ideas for whole class/group discussion. Including discussion questions/talking points/dilemmas

1. First activity (using the platform): while organised into groups, students must choose a sequence of the story, with words representative of the meanings of the film and build a video-narrative (video-graphic synthesis) choosing three moments/excerpts of the films and presenting its plot.

2. Alternative of first activity (for the piloting phase): in groups, create a narrative with simple drawings representing the main idea(s) of the film according to your interpretation(s). See template attached.

3. Second activity: in pairs of groups, each group from class A shares with a group of class B its video-narrative. Each group chooses a title and a short explanation about the micro-story of the other group. 4. Alternative of second activity (for the piloting phase): Each group exchanges their narrative with another group, who has to interpret it and put a title on it.

\begin{tabular}{ll}
\hline $\begin{array}{l}\text { Reflection activity } \\
\text { (reflect on learning } \\
\text { objectives) }\end{array}$ & $\begin{array}{l}\text { The teacher returns to the question "what is a home?" to the whole } \\
\text { class, and each group responds with three key-words. }\end{array}$ \\
\hline $\begin{array}{l}\text { Cultural artefact } \\
\text { (May be part of the } \\
\text { session or extra) }\end{array}$ & $\begin{array}{l}\text { Students must create a video-graphic synthesis of the cultural text. } \\
\text { Students choose the excerpts they feel the most relevant and rebuild the } \\
\text { narrative. Afterwards, they choose a title for it and elaborate a short } \\
\text { commentary about the video-graphic synthesis of the other } \\
\text { participating class. }\end{array}$ \\
\hline
\end{tabular}

\section{Appendix B}

Abstract of the four materials used across educational levels and across sessions (see Table 2).

\section{Abstract of Ant (Ocker, [43])}

This film, part of the Animanimals series by Julie Ocker, depicts the systematic and collective life of an ant colony. The military precision of the ants is an apt catalyst to discuss the social bonds that define contemporary communities, including Europe as a whole. The ants work together perfectly, except for the plucky little ant who leads the story. This ant has his own way of doing things; his creative spirit causes an important intervention in the systematised workings of the community. The other ants join in. At the end of the film, the ant believes the master ant will be angry with him - and so do we. But all is well: the master ant congratulates him for his successful thinking. This is a joyful, vibrant piece of animation with a clear and affirmative message about the role of innovation and outside-the-box thinking in developing new strategies with which society can move forward. Children aged 8 to 11 years old will be able to structure a debate around these themes by considering this short film.

\footnotetext{
Abstract of Papa's Boy (Lemmetty [44])

This CGI short film, co-produced in Ireland and Finland, is about masculinity and femininity. The film was originally prepared as part of a project celebrating the music of Chopin. Although knowledge of Chopin is by no means requisite to the success of the film, this information adds a layer of European context to the film's value as a pedagogical tool. A little mouse, coded as a boy, is not living up to his father's expectations. While his father was a famous boxer, he is interested in ballet dancing and dances around in a tutu. However, his moment to shine comes when a cat attacks his father. Through ballet, the boy escapes the clutches of the cat and save his father. The moral of the story is clear: celebrate difference and love your loved ones for who they are. Children aged 4-7 will be able to respond broadly to this film, while children aged 8 to 11 years old will be able to create a reflexive debate around the issues this raises: gender nonconformity, family, tolerance- even the ethics of the food chain between cats and mice. It is interesting to consider how gender roles might, or might not, enter the dialogue when this film is used with 12to 15-year-olds.
} 


\begin{abstract}
Changeons! (Guistozzi, [45])
The relationship between the ocean and human civilization is put under a lens in this challenging panoramic depiction of a changing coastal urban environment. What begins as a harmonious pastoral depiction of human life on the seafront quickly darkens into a polluted urban sprawl of skyscrapers belching smog and oil into the water and the sky. The sustainability of city life is called into question: readers are able to contemplate, how secure is the relationship between urban development and the natural world? How can continued economic and population growth be developed in a way that promotes harmony rather than destruction over the natural world? Indeed, the issue of time is brought up by the visual narrative- how much time goes by as the world changes, how fast is too fast? The intricate panoramas of the changing urban scene do not exert their moral stance over the reader-rather, the reader must decode the patterned representation of advancing urban life to decode the moral of the story. This picture book is an excellent example of a work that depicts issues of sustainable development and climate change without patronising its reader. With this in mind, it is very suitable for 12- to 15-year-olds.
\end{abstract}

\begin{abstract}
Baboon on the Moon (Duriez [40])
This classic stop motion film was made in the UK in the early 2000s and used by the British Film Institute as part of their starting stories resource. A simple visual narrative is embedded with a complex set of themes: a baboon, stationed on the moon, plays his trumpet mournfully as he looks at Earth from afar. The strength of this philosophical and affective film is its potential for discourse in numerous directions: the displacement of the baboon creates an opportunity to consider deforestation; the space setting provides a sense of universality to the themes of home, homelessness and nostalgia; and the placement of a baboon on the moon narrates the real-life use of animals in space travel in the twentieth century. This multifaceted way of considering home indicates a high usability in every age group: out of all the books and films in the corpus, this film is highlighted for use with 4- to 7-year-olds, 8- to 11-year-olds and 12- to 15-year-olds.
\end{abstract}

\title{
References
}

1. Maine, F.; Cook, V.; Lähdesmäki, T. Reconceptualizing cultural literacy as a dialogic practice. Lond. Rev. Educ. 2019, 17, 383-392. [CrossRef]

2. Hirsch, E.D. Culture and literacy. J. Basic Writ. 1980, 3, 27-47. [CrossRef]

3. Giroux, H.A. Border Crossings: Cultural Workers and the Politics of Education; Routledge: New York, NY, USA, 1992.

4. Kaufer, D.S. Cultural Literacy: A Critique of Hirsch and an Alternative Theory. ADE Bull. 1989, 94, 23-28. [CrossRef]

5. Riecken, T.J.; Court, D. Extending cultural literacy. J. Educ. Thought 1992, 26, 152-163.

6. Buber, M.I.; Smith, R.G. I and Thou, 2nd ed.; T. and T. Clark: Edinburgh, UK, 1958.

7. Farmer, L. Pro-Active Digital Citizenship: Strategies for Educators. In Handbook of Research on Positive Scholarship for Global K-20 Education; IGI Global: Hershey, PA, USA, 2018; pp. 62-79.

8. European Union. Recommendation of the European Parliament and of the Council of 18th December 2006 on Key Competences for Lifelong Learning; European Union: Washington, WA, USA, 2006.

9. DIALLS. Dialogue and Argumentation for Learning Literacy Skills. 2018. Available online: https://dialls2020.eu/ (accessed on 3 June 2021).

10. Tienda, M. Diversity Inclusion: Promoting integration in higher education. Educ. Res. 2013, 42, 467-475. [CrossRef]

11. Kim, M.-Y.; Wilkinson, I.A. What is dialogic teaching? Constructing, deconstructing, and reconstructing a pedagogy of classroom talk. Learn. Cult. Soc. Interact. 2019, 21, 70-86. [CrossRef]

12. Asterhan, C.S.C.; Howe, C.; Lefstein, A.; Matusov, E.; Reznitskaya, A. Controversies and consensus in research on dialogic teaching and learning. Dialog. Pedagog. Int. Online J. 2020, 8, 1-16. [CrossRef]

13. Alexander, R. Developing dialogic teaching: Genesis, process, trial. Res. Pap. Educ. 2018, 33, 561-598. [CrossRef]

14. Reznitskaya, A.; Wilkinson, I.A.G. The Most Reasonable Answer: Helping Students Build Better Arguments Together; Harvard Education Press: Cambridge, UK, 2017.

15. Muhonen, H.; Rasku-Puttonen, H.; Pakarinen, E.; Poikkeus, A.-M.; Lerkkanen, M.-K. Scaffolding through dialogic teaching in early school classrooms. Teach. Teach. Educ. 2016, 55, 143-154. [CrossRef]

16. Chinn, C.A.; O'Donnell, A.M.; Jinks, T.S. The Structure of Discourse in Collaborative Learning. J. Exp. Educ. 2000, 69, 77-97. [CrossRef]

17. Kumpulainen, K.; Lipponen, L. Productive interaction as agentic participation in dialogic enquiry. In Dialogues: Understanding and Promoting Productive Interaction; Littleton, K., Howe, C., Eds.; Routledge: London, UK, 2010.

18. Michaels, S.; O'Connor, C.; Resnick, L.B. Deliberative Discourse Idealized and Realized: Accountable Talk in the Classroom and in Civic Life. Stud. Philos. Educ. 2008, 27, 283-297. [CrossRef] 
19. O'Connor, C.; Larusso, M. Working with a Low-Inference Discourse Observation Tool: What Can We See; Annual Educational Research Association: Philadelphia, PA, USA, 2014.

20. Rapanta, C.; Garcia-Mila, M.; Remesal, A.; Gonçalves, C. The challenge of inclusive dialogic teaching in public secondary school. Comunicar 2021, 66, 21-31. [CrossRef]

21. Reznitskaya, A.; Gregory, M. Student Thought and Classroom Language: Examining the Mechanisms of Change in Dialogic Teaching. Educ. Psychol. 2013, 48, 114-133. [CrossRef]

22. Sedova, K. A case study of a transition to dialogic teaching as a process of gradual change. Teach. Teach. Educ. 2017, 67, 278-290. [CrossRef]

23. Pianta, R.C.; La Paro, K.; Hamre, B.K. Classroom Assessment Scoring System (CLASS); Paul H. Brookes: Baltimore, UK, 2008.

24. Pianta, R.C.; Whittaker, J.E.; Vitiello, V.; Ruzek, E.; Ansari, A.; Hofkens, T.; De Coster, J. Children's school readiness skills across the pre-K year: Associations with teacher-student interactions, teacher practices, and exposure to academic content. J. Appl. Dev. Psychol. 2020, 66, 101084. [CrossRef]

25. Lawson, P.O.; Sinclair, J.M.; Coulthard, R.M. Towards an Analysis of Discourse: The English Used by Teachers and Pupils. TESOL Q. 1977, 11, 203. [CrossRef]

26. Muhonen, H.; Verma, P.; von Suchodoletz, A.; Rasku-Puttonen, H. Exploring types of educational classroom talk in early childhood education centres. Res. Pap. Educ. 2020, 1-22. [CrossRef]

27. Rasku-Puttonen, H.; Lerkkanen, M.-K.; Poikkeus, A.-M.; Siekkinen, M. Dialogical patterns of interaction in pre-school classrooms. Int. J. Educ. Res. 2012, 53, 138-149. [CrossRef]

28. Bautista, A.; Moreno-Núñez, A.; Ng, S.-C.; Bull, R. Preschool Educators' Interactions with Children About Sustainable Development: Planned and Incidental Conversations. Int. J. Early Child. 2018, 50, 15-32. [CrossRef]

29. Bateman, A. Responding to children's answers: Questions embedded in the social context of early childhood education. Early Years 2013, 33, 275-288. [CrossRef]

30. Theobald, M.; Kultti, A. Investigating Child Participation in the Everyday Talk of a Teacher and Children in a Preparatory Year. Contemp. Issues Early Child. 2012, 13, 210-225. [CrossRef]

31. Hännikäinen, M.; Rasku-Puttonen, H. Promoting children's participation: The role of teachers in preschool and primary school learning sessions. Early Years 2010, 30, 147-160. [CrossRef]

32. Mercer, N.; Dawes, L.; Staarman, J.K. Dialogic teaching in the primary science classroom. Lang. Educ. 2009, 23, 353-369. [CrossRef]

33. Vrikki, M.; Wheatley, L.; Howe, C.; Hennessy, S.; Mercer, N. Dialogic practices in primary school classrooms. Lang. Educ. 2019, 33, 85-100. [CrossRef]

34. Hardman, F.; Wall, K.; Mroz, M.; Smith, F. Interactive whole class teaching in the National Literacy and Numercy Strategies. Br. Educ. Res. J. 2004, 30, 395-411. [CrossRef]

35. MacNeilley, L.H.; Nystrand, M.; Gamoran, A.; Kachur, R.; Prendergast, C. Opening Dialogue: Understanding the Dynamics of Language and Learning in the English Classroom; Teachers College Press: New York, NY, USA, 1997.

36. Davies, M.; Kiemer, K.; Meissel, K. Quality Talk and dialogic teaching_An examination of a professional development programme on secondary teachers' facilitation of student talk. Br. Educ. Res. J. 2017, 43, 968-987. [CrossRef]

37. Scott, P.; Mortimer, E.F.; Aguiar, O.G. The tension between authoritative and dialogic discourse: A fundamental characteristic of meaning making interactions in high school science lessons. Sci. Educ. 2006, 90, 605-631. [CrossRef]

38. Duriez, C. Baboon on the Moon; British Film Institute: London, UK, 2002.

39. Ocker, J. Ant; Studio Film: Bilder, Germany, 2017.

40. Lemmetty, L. Isän Poika [Papa's Boy]; Lasten Keskus: Helsinki, Finland, 2010.

41. Guistozzi, F. Changeons! [Let's change!]; La Joie de Lire: Geneva, Switzerland, 2017.

42. Fisher, R. Dialogic teaching: Developing thinking and metacognition through philosophical discussion. Early Child Dev. Care 2007, 177, 615-631. [CrossRef]

43. UNESCO Institute for Statistics. International Standard Classification of Education (ISCED); UNESCO Institute for Statistics: Montreal, QC, Canada, 2011.

44. Hennessy, S.; Rojas-Drummond, S.; Higham, R.; Márquez, A.M.; Maine, F.; Ríos, R.M.; García-Carrión, R.; Torreblanca, O.; Barrera, M.J. Developing a coding scheme for analysing classroom dialogue across educational contexts. Learn. Cult. Soc. Interact. 2016, 9 , 16-44. [CrossRef]

45. Howe, C.; Mercer, N. Commentary on the papers. Lang. Educ. 2016, 31, 83-92. [CrossRef]

46. Lähdesmäki, T.; Koistinen, A.K.; Ylönen, S.; Zaleskienė, I.; Duoblienė, L.; Kairè, S.; Harrison, F. Policy Brief: Developing Education Policies in Europe to Enhance Cultural Literacy; DIALLS: London, UK, 2019. 